УДК 902 (571.65) (092)

\title{
О ЖИЗНЕННОМ ПУТИ И НАУЧНОЙ ДЕЯТЕЛЬНОСТИ Т. М. ДИКОВОЙ
}

\author{
А. И. Лебединцев \\ ФГБУН Северо-Восточный комплексный научно-исследовательский институт \\ им. Н. А Шило ДВО РАН, г. Магадан \\ E-mail: lebedintsev@neisri.ru
}

\begin{abstract}
Представлены биографические данные и основные результаты научной деятельности сотрудника лаборатории истории, археологии и этнографии СВКНИИ ДВНЦ АН СССР, археолога Т. М. Диковой. В 1972-1979 гг. она проводит раскопки на юге Камчатки, исследует несколько десятков археологических объектов, изучает древнеительменскую культуру, выявляет южные границы, связи с соседними культурами. Т. М. Дикова предложила периодизацию для древних стоянок южной Камчатки и установила, что айны постоянно на юге Камчатки не обитали, но оказывали определенное влияние на культуру ительменов этой части Камчатки.
\end{abstract}

Ключевые слова: история археологических исследований, древние стоянки, айны, ительмены, этногенез, этнокультурные связи, южная Камчатка, Т. М. Дикова.

DOI: 10.34078/1814-0998-2019-4-109-117

Тамара Митрофановна Дикова (урожденная Иванова) родилась 12 июня 1933 г. в семье Митрофана Ивановича Иванова - лесничего Парголовского леспромхоза Усьятского района Калининской области ([Дикова Т. М. Личное дело]; Дикова (Кирьяк), 2003; СВКНИИ..., 2010). В 1945 г. отец ушел из семьи, оставив на руках жены, Марфы Васильевны, двух дочерей. Детство и юность Тамары проходили в Ленинградской области. В 1943 г. она поступила в начальную школу, затем перевелась в семилетнюю, которую окончила в 1949 г. Из-за сложного материального положения девушка пошла работать ткачихой на ткацкую фабрику комбината «Красный Маяк» в Ленинграде. В 1950 г. она поступила в Ленинградское городское дошкольное педагогическое училище, которое окончила в 1953 г., получив специальность воспитателя детского сада. После этого она недолго проработала в детском саду и в апреле 1954 г. уехала в Северо-Казахстанскую область, где сначала трудилась прицепщицей в тракторной бригаде в зерносовхозе «Украинский» (Пресновский район), а потом учителем биологии и физкультуры в Новорыбинской семилетней школе.

В сентябре 1955 г. Тамара Митрофановна вернулась в Ленинград к работе воспитателем в детском саду.

В 1958 г. она становится студенткой-заочницей исторического факультута Ленинградского государственного университета им А. А. Жда-

(С Лебединцев А. И., 2019 нова и занимается по индивидуальному плану при кафедре археологии. В это время выезжает в археологические экспедиции. В полевой сезон 1959 г. участвует в Байкальской экспедиции, в раскопках стоянки Улан-Хада, затем в 1960 и 1961 г. в Красноярской экспедиции, которая занималась исследованием могильников карасукской и афанасьевской культур.

В 1959-1962 гг. Тамара Митрофановна работает внештатным старшим лаборантом Ленинградского отделения Института археологии АН CCCP.

В ее характеристике 1962 г., подписанной доктором исторических наук, профессором М. П. Грязновым, сообщалось, что «... в условиях полевых археологических работ она проявила себя как усердный трудолюбивый, преданный делу сотрудник, внимательно и ответственно выполняющий данные ему поручения. С первого же года ее работ в экспедичии ей было поручено ведение всех видов первичной обработки получаемого в раскопках археологического вещевого материала-учет, описи, очистка, иифровка, упаковка. Она успешно справлялась с этого рода работами, выступая часто в роли руководителя этих работ ...

В течение трех зимних периодов она работала в качестве лаборанта по камеральной обработке коллекиий экспедиции. Здесь она выполняла роль старшего лаборанта. На ее долю выпадали наиболее сложные и ответственные работы. Она хорошо освоила различные виды реставрации археологических материалов. В част- 
ности, научилась очень искусно реставрировать керамику.

Учитыввая все сказанное, я охотно рекомендую Т. М. Дикову как усердного, инициативного и ответственного в своем деле работника и как умелого, опьтнного лаборанта-археолога. Вместе с тем в экспедиции она принимала участие в самих раскопках. Ей поручалось ведение раскопок отдельных объектов: самостоятельный раскоп на поселении, курган, могила. Она хорошо усвоила методику раскопок могил со сложными каменными сооружениями» [Дикова Т. М. Личное дело].

В 1962 г. Тамара Митрофановна выходит замуж за Н. Н. Дикова, переезжает в Магадан и работает сначала лаборантом, затем старшим лаборантом лаборатории археологии, истории и этнографии СВКНИИ (фото 1). Она участвует в четырех археологических экспедициях.

Ее первой опубликованной научной работой была статья, посвященная исследованию поселения Канчалан (Дикова, 1964), которая затем была переведена на английский язык и напечатана в журнале «Arctic Anthropology» (Dikova, 1965). Она проанализировала материалы, полученные в результате раскопок В. В. Нарышкина в 1953-1954 гг. Это поселение состояло из двенадцати западин от жилищ округлой формы. В раскопанных жилищах выявлены слегка углубленные в землю очаги; найдены каменные скребла, кирка-мотыга из моржового клыка, костяной отжимник, фрагменты керамических сосудов с наружными налепными «ушками». Автор отмечает, что в материалах этой стоянки есть много общего с приморской эскимосской культурой и с культурой охотников на оленей, обитавших по p. Анадырь. Данная публикация существенно дополнила характеристику канчаланской культуры.

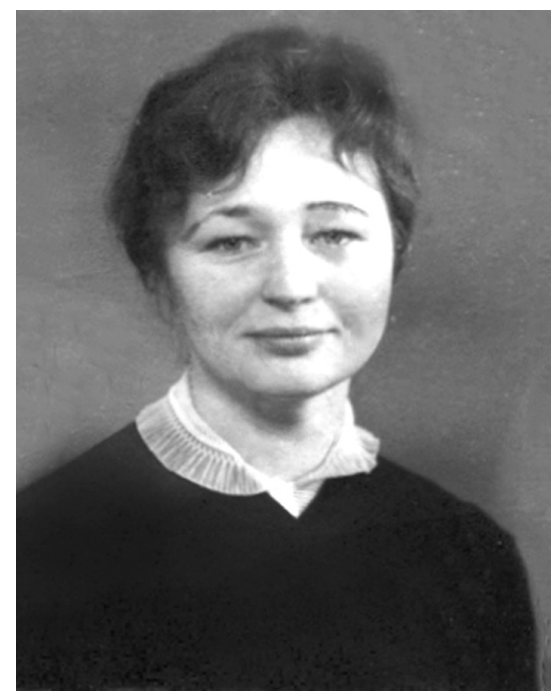

Фото 1. Тамара Митрофановна Дикова, 1962 г. Foto 1. Tamara M. Dikova, 1962
T. М. Диковой в соавторстве с геологом В. В. Красковым опубликована статья о поселении морских охотников рубежа н. э., которое было обнаружено в юго-восточной части п-ова Аачим на побережье Центральной Чукотки (Красков, Дикова, 1966). В публикации дано описание месторасположения этого поселения, находок из культурного слоя и подъемного материала, представленного в основном каменным материалом, а также фрагментами одного керамического сосуда. Выявлены обгорелые конструкции жилища с каркасом из бревен плавника. Сделан вывод о том, что это поселение принадлежит к одному из ранних этапов древнеэскимосской культуры.

Уже первые публикации Т. М. Диковой показали ее как опытного и квалифицированного исследователя.

В 1968 г. она заочно окончила исторический факультет Ленинградского государственного университета с присвоением ей квалификации археолога, историка.

Темы ее исследований - «Археология южной Камчатки в связи с проблемой обитания там айнов» и «Древние культуры южной Камчатки и их роль в истории Дальнего Востока». На протяжении ряда лет $(1972,1973,1975,1977,1979$ г.) Т. М. Дикова работала в самых труднодоступных районах южной Камчатки - мыс Лопатка, Налычево, Явино, Курильское озеро и на о. Шумшу. Она являлась руководителем Южно-Камчатского археологического отряда СВКНИИ, входящего в Северо-Восточно-Азиатскую комплексную археологическую экспедицию (СВАКАЭ), возглавляемую Н. Н. Диковым. На южной Камчатке ею были открыты несколько десятков археологических памятников. Она изучает древнеительменскую культуру, выявляет южные границы, связи с соседними культурами и их роль в истории Дальнего Востока [Дикова Т. М. Археология..., 1977].

Ее первые самостоятельные археологические работы по теме исследования начались в 1972 г. [Дикова Т. М. Отчет..., 1973]. Результаты археологических раскопок в 1973 и 1975 г. представлены в отчетах СВКНИИ [Дикова Т. М. Отчет..., 1975, 1976].

Были обследованы памятники восточного побережья южной Камчатки в районе Авачинской губы (Авача, Халактырка) и Авачинского залива (Налычево).

При устье р. Авача Т. М. Дикова проводила раскопки стоянки тарьинской культуры (Дикова, 1979a) (фото 2). Исследования этой многослойной стоянки сделали данный памятник опорным и эталонным. В нижнем культурном слое стоянки Авача при расчистке пола жилища обнаружена древнейшая на Дальнем Востоке плетенная из растительных волокон ткань, возраст которой бо- 


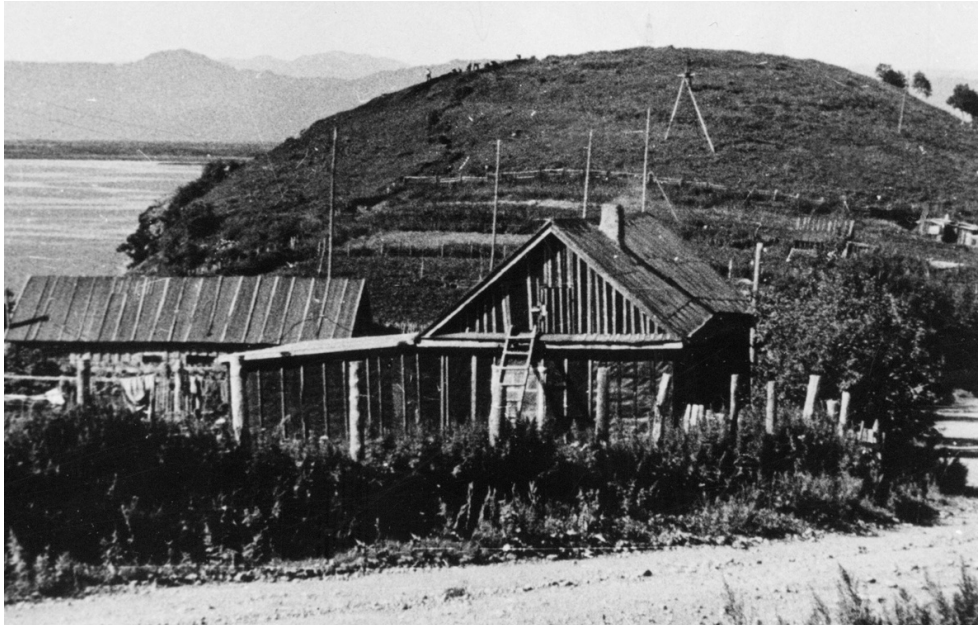

Фото 2. Вид на стоянку Авача. На вершине сопки слева ведутся раскопки

Foto 2. View of the Avacha site, excavation being conducted on the left slope of the hill

лее 5 тыс. лет (Дикова, 1979в). Выше, по обрыву сопки, разобраны остатки «раковинной кучи» с костями животных и птиц, найден наконечник остроги и наконечник поворотного гарпуна из кости (Дикова, 1976б).

На южном склоне м. Налычева и северовосточном берегу озера Т. М. Дикова в 1972 г. обнаружила поселение с огромным количеством углубленных жилищ. В 1975 г. она провела разведочные маршруты в устье р. Налычева: осмотрены берега от самого устья до 6 км вверх по течению, а также берега р. Озерная (левого притока р. Налычева), рекогносцировочные работы выполнены у м. Налычева [Дикова, 1973].

На северо-восточном берегу оз. Налычева отрядом Т. М. Диковой проведены раскопки одного жилища в 1972 г. и части еще одного жилища в 1975 г. Жилище на м. Налычева было со слегка углубленным котлованом. Около очага жилища обнаружены фрагменты цилиндрического плоскодонного сосуда, по внутреннему краю которого имелся двойной валик, а внешняя поверхность гладкостенная. Прослежены остатки горелого легкого каркаса из тонких жердей (Дикова, 1976б). Проведенные исследования жилищ на оз. Налычева показали, что это поселение является разновременным (Дикова, 1983) (фото 3).

На м. Лопатка Т. М. Дикова проводила археологические исследования в течение трех полевых сезонов. В 1972 г. там были выполнены разведочные работы и установлена большая перспективность изучения этого района, а в 1973 и 1975 г. уже осуществлялись стационарные раскопки. Были выявлены четыре местонахождения, на которых собраны обильные материалы - от более ранних, галечных орудий палеолитического облика до поздних, датируемых XVII в. (Диков, Дикова, 1973; Дикова, 1974в, 1979в, г).
На участке Лопатка IV произошло переотложение артефактов разновременных культурных слоев, что создавало сложность датировки галечного комплекса орудий (Дикова, 1983). Комплекс каменных орудий палеолитического облика (чопперы, чоппинги, массивные скребла, наконечники на треугольных пластинчатых сколах), по мнению Т. М. Диковой, характерен для зоны сибирского палеолита (Дикова, 1979б; Dikova, 1979). Аналогии прослеживаются с верхнепалеолитическими культурами Вьетнама, Монголии, Приморья, Японии, Курильских островов и Северной Америки. Исследовательница полагала, что это факт свидетельства миграции палеолитического человека в позднем плейстоцене из Азии в Америку по островам Тихого океана. Однако вопрос о датировке палеолитического комплекса Лопатка IV остается пока открытым (Дикова, 1979г). Высказываются сомнения о палеолитическом возрасте галечного комплекса (Гусев и др., 2013).

В то же время предполагалось, что другие находки, представленные листовидными наконечниками, горбатыми ножами, скребками с рукоятями,

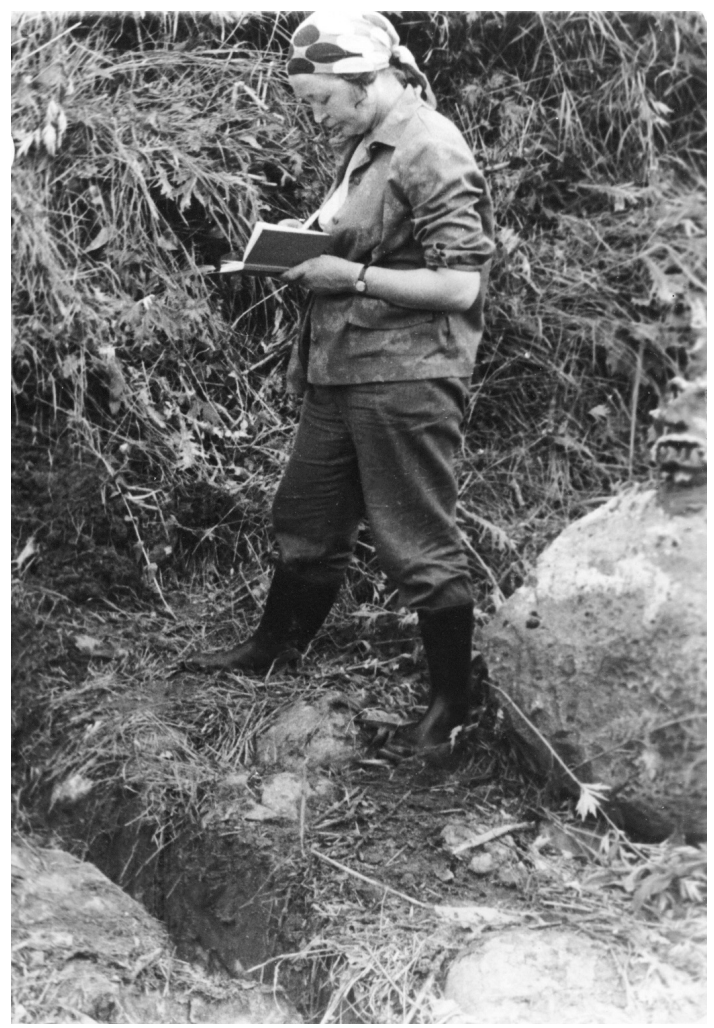

Фото 3. Т. М. Дикова ведет полевой дневник на раскопках

Foto 3. T. M. Dikova keeping the field diary at the excavation 
острообушковыми теслами, относятся к комплексу орудий тарьинской культуры (Дикова, 1983).

Местонахождение Лопатка III представляет собой развеянную «раковинную кучу», состоящую из костей морских животных и раковин моллюсков. Здесь материал также смешанный и переотложенный. Основная масса каменных орудий с этого участка сходна с находками из Лопатки IV, и, по-видимому, они являются тарьинскими.

На участке Лопатка II был собран в основном подъемный материал, представленный большой коллекцией каменных разнообразных орудий и несколькими экземплярами костяных изделий (Дикова, 1983). По всей площади равномерно располагались раковины моллюсков и раздробленные кости птиц и животных. В целом весь материал этого местонахождения характеризуется

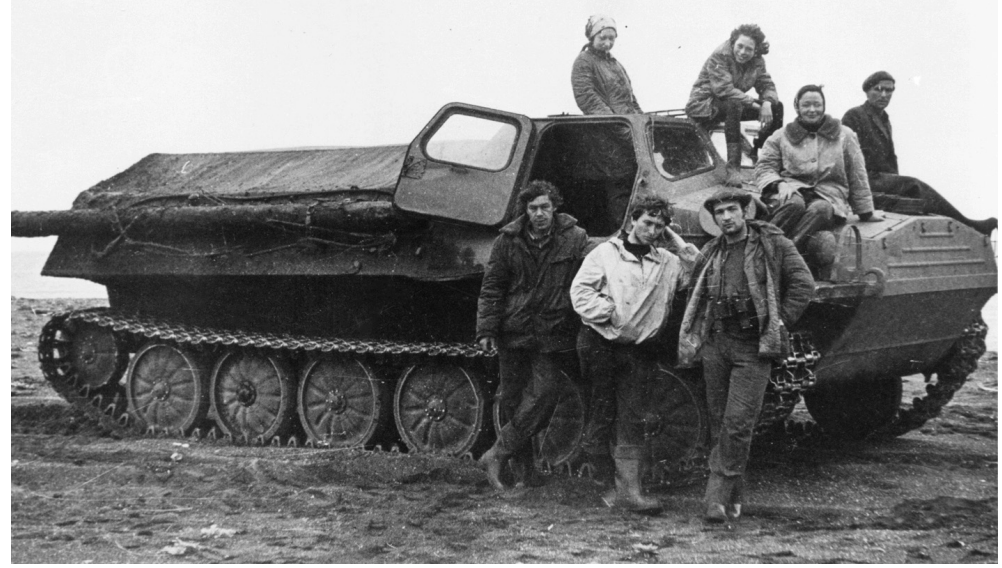

Фото 4. Участники экспедиции у вездехода, побережье Охотского моря на южной Камчатке (район устья рр. Голыгина и Опала)

Foto 4. Expedition members at the off-roader, southern Kamchatka's coast of the Sea of Okhotsk (mouth of the Golygina and Opala rivers)

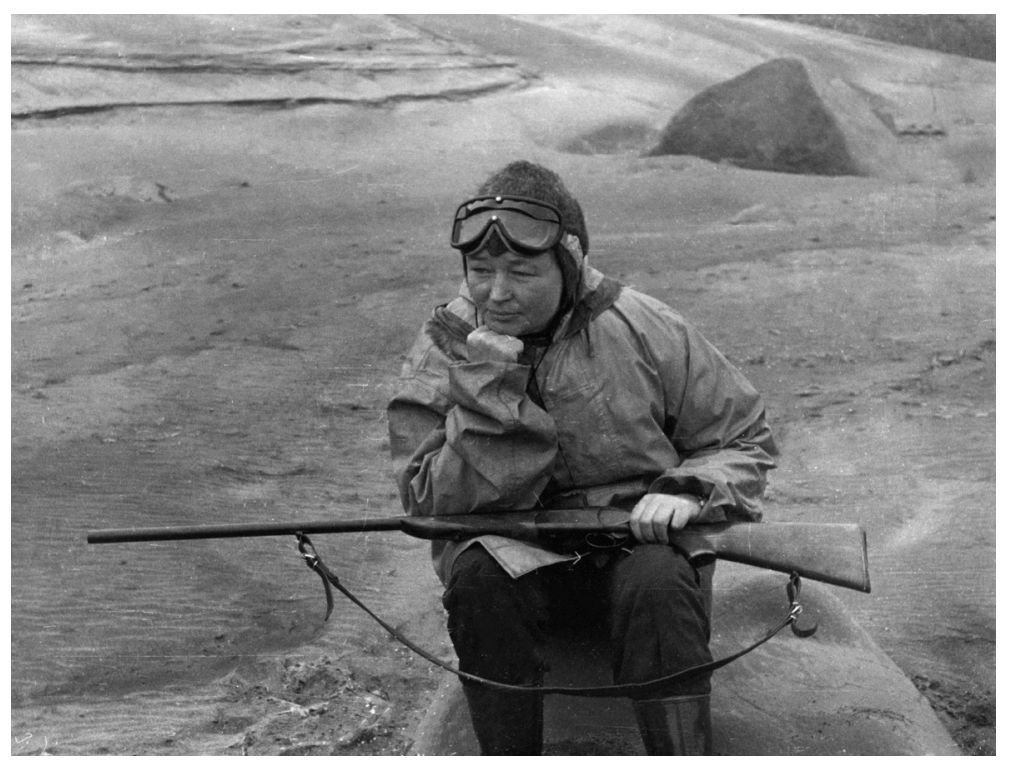

Фото 5. Т. М. Дикова на стоянке Явино, 1977 г.

Foto 5. T. M. Dikova at the Yavino site, 1977 как однородный. Предварительно его датировали рубежом нашей эры (Дикова, 1976б).

На местонахождении Лопатка І работы велись несколько лет ([Дикова, 1973], 1974б). Культурный слой оказался переотложенным. В центре стоянки располагалась «раковинная куча» с большим количеством обломков раковин моллюсков, костей морских и сухопутных животных, птиц и рыб. Эта «раковинная куча», где обнаружены фрагменты сосудов Найдзи, отнесена Т. М. Диковой к верхнему слою. Там были собраны каменные и костяные изделия. В нижней части найдены остатки более древних жилищ с каменным инвентарем. Были выявлены два жилища, одно из которых датировано началом I тыс. н. э. Т. М. Дикова сделала важный вывод о том, что в этом месте на м. Лопатка в середине XVII в. обитало метисное население, образовавшееся в результате смешения ительменов и «курильцев» (они селились на время сезонной охоты), и что там происходило соприкосновение двух культур - ительменской и айнской (Дикова, 1976б, 1983).

Еще один участок - Лопатка V, обследованный Т. М. Диковой, находится на Тихоокеанском побережье м. Лопатка. Там, среди выдува дюн были обнаружены двузубый наконечник гарпуна из кости, а также несколько каменных орудий и отщепы. Эти находки, по мнению Т. М. Диковой, одновременны с материалом местонахождения Лопатка I.

В 1973 и 1975 г. Т. М. Дикова проводила раскопки поселения Андриановка (Дикова, 1983), обследовала поселения у оз. Гнилое и у руч. Рябухина.

Тамара Митрофановна прошла маршрутом В. И. Иохельсона 1910 1911 гг. по южной Камчатке. Разведочные работы осуществлены в окрестностях м. Сиюшк. На м. Сиюшк Курильского озера ее отряд раскопал два жилища, в которых обнаружены каменные изделия и керамика Найдзи.

В 1977 г. проведены работы на юго-западном побережье южной Камчатки (Дикова, 1978) (фото 4, 5). Недалеко от устья р. Озерная на левом берегу Шестой речки обнаружено поселение, состоящее из нескольких жилищ. На этом местонахождении были заложены шурфы. В устье p. Явина на левом берегу зафиксированы девять разновременных стоянок. Жилища расположены на дюнах 
между руслом реки и побережьем моря на расстоянии 2.5 км. На побережье Охотского моря на левом берегу р. Кошегочек обследовано древнеительменское поселение, где сделана зачистка обнажений и заложена траншея. При осмотре окрестностей Усть-Большерецка на правом берегу р. Амчагачи обнаружены три стоянки, одна из которых оказалась в центральной части поселка, две другие расположены на левом и правом берегах в устье кл. Хайково, впадающего в Амчагачу (Дикова, 1983).

В 1979 г. были продолжены раскопки стоянки Явино, выполнена разведка по левому берегу Правой Явиной речки в устье Левой Явиной (фото 6).

На Камчатке Т. М. Дикова собрал пробы древесного угля для радиоуглеродного датирования, по которым получены датировки в лаборатории СВКНИИ (Шило и др., 1977). Новые данные дополнили и уточнили возраст археологических памятников южной Камчатки.

Предварительные результаты археологических работ на южной Камчатке публиковались в различных сборниках (Дикова, 1974б, 1976в, 1979а).

Исследования Т. М. Диковой были обобщены и представлены в большой монографии о древних культурах южной Камчатки, вышедшей уже после ее смерти (Дикова, 1983). В предисловии к этой книге Н. Н. Диков высоко оценил вклад Тамары Митрофановны в исследование далекого прошлого Камчатки и отметил, что эти археологические источники были во многом неожиданными, интересными и очень информативными, проливающими новый и вполне определенный свет на поставленную перед ней сложную проблему этнической принадлежности древних обитателей «Курильской землицы» (Там же. С. 6). Сообщение о выходе этой книги было помещено в одном из японских журналов (Кикути, 1985), что говорит о заинтересованности японских археологов результатами исследований Т. М. Диковой на южной Камчатке. Недавно в Японии опубликован иллюстрированный каталог археологических материалов с южной Камчатки, собранных Т. М. Диковой и находящихся в СВКНИИ ДВО PAH (Takase, Lebedintsev, 2019).

Кроме того, Тамара Митрофановна участвовала в археологических экспедициях Н. Н. Дикова. В 1962 г. они вместе на бате прошли р. Камчатка, а осенью на лодке - р. Пенжина. В 1965 г. она принимала участие в раскопках древнеэскимосского Чинийского могильника. В течение трех полевых сезонов (1971, 1973 и 1974 г.) Т. М. Дикова проводила раскопки стоянки Сибердик в зоне затопления Колымской ГЭС в качестве заместителя начальника экспедиции [Дикова Т. М. Сводный..., 1974]. Периодически она выезжала на раскопки Ушковской палеолитической стоянки на Камчат- ке (1962, 1964, 1971, 1976, 1980 г.) (Диков, Дикова, 1972, 1973, 1974).

В 1971 г. Т. М. Дикова стала младшим научным сотрудником, а с 1974 г. - соискателем ученой степени кандидата исторических наук.

В 1972 г. в Магадане проходила 3-я сессия Дальневосточных исторических чтений по проблемам истории Северо-Востока СССР, посвященная 50-летию образования СССР и 50-летию освобождения Дальнего Востока от интервентов и белогвардейцев, на которой Тамара Митрофановна выступила с докладом «Состояние археологической изученности южной Камчатки» (Дикова, 1976а).

В 1973 г. в «Краеведческих записках» Чукотского окружного краеведческого музея опубликована совместная работа с В. А. Воробьевым «Новый памятник бирниркской культуры на севере Чукотки» (Дикова, Воробьев, 1973). В ней описаны находки подъемного материала геолога В. А. Воробьева со стоянки 2, обнаруженные в 1971 г. в северо-восточной части п-ова Аачим. В осыпи большого холма (остатке древнеэскимосского жилища) встречены каменные и костяные орудия, в том числе наконечник поворотного гарпуна из рога оленя; обломки керамических сосудов с оттисками

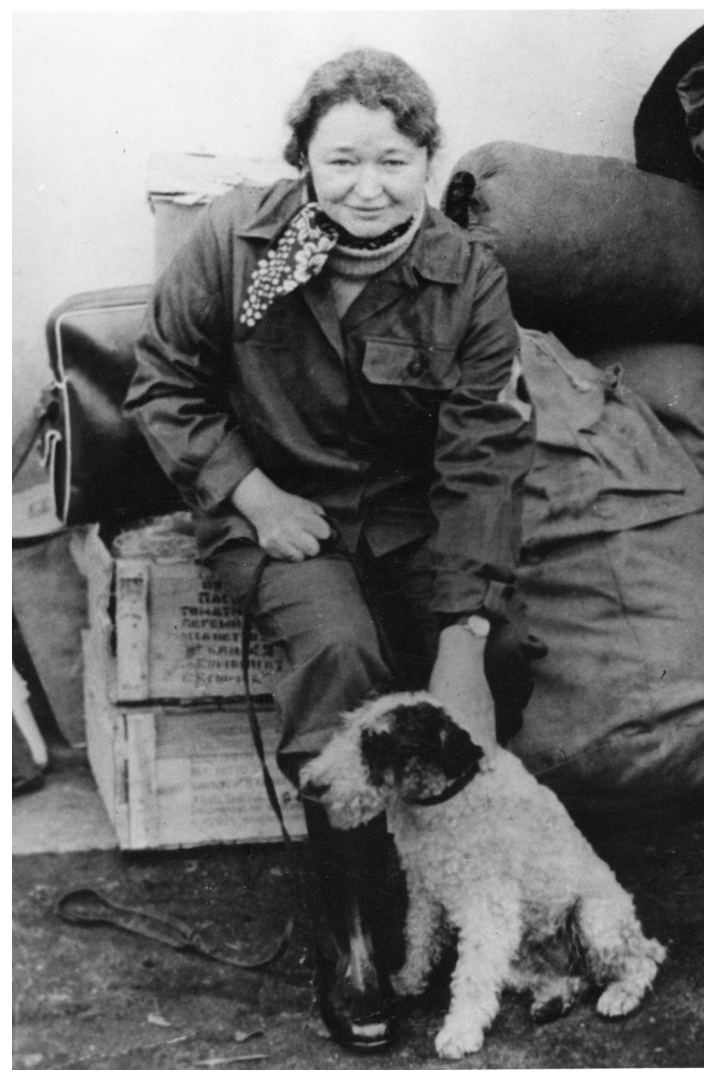

Фото 6. Т. М. Дикова в экспедиции. Поселок Озерновский, 1979 г.

Foto 6. T. M. Dikova in the expedition, settlement of Ozernovsky, 1979 
ткани на поверхности, а также один фрагмент со штамповым орнаментом в виде тройного ряда полукружков. Поселение было отнесено к бирниркской культуре и датировано V-VIII вв. Эта поздняя эскимосская культура исследована мало, и любые новые материалы имеют важное значение.

В 1974 г. Магаданское книжное издательство выпустило в свет брошюру «Археологические памятники Магаданской области», написанную на основе опубликованных источников (Дикова, 1974a). В ней дается точное описание местонахождений археологических памятников по районам, краткая характеристика 137 стоянок, поселений и могильников, приведена история их открытия.

В 1977 г. Т. М. Диковой присвоено ученое звание младшего научного сотрудника по специальности «Археология».

Тамара Митрофановна принимала участие в XIV Международном Тихоокеанском конгресce (1979 г.), выступив с докладом «Взаимосвязи между южно-камчатским и американским палеолитом» (Дикова, 1979б; Dikova, 1979), а также подготовила стенды с материалами важнейших открытий в археологии Северо-Востока для выставки к этому конгрессу.

Одна из ее последних работ, написанная при жизни, посвящена лабреткам - оригинальным украшениям, характерным для тарьинской культуры (Дикова, 1980). Она определила способы и места ношения этих украшений (в отверстиях обеих щек, по две в губе - верхней или нижней, одновременно в носовой перегородке и в нижней губе), выделив по форме четыре группы - шпилькообразные с острым и широким прямым концами, шляпо- и запонкообразные. Лабретки вставлялись в прорези различных участков лица.

T. М. Диковой написано более 20 научных работ, известных не только в нашей стране, но и за рубежом. Результаты ее научных исследований отражены в публикациях о деятельности лаборатории истории и археологии СВКНИИ ДВО РАН (Лебединцев, 2000, 2013).

Тамара Митрофановна вела большую общественную работу. Она руководила археологической секцией Совета Магаданского областного отделения Всероссийского общества охраны памятников истории и культуры. Подготовила к изданию каталог археологических памятников Магаданской области (Дикова, 1974a). За активную деятельность в этом обществе, за лекционную пропаганду и популяризацию археологических знаний награждена четырьмя Почетными грамотами общества, памятным знаком.

Т. М. Дикову неоднократно избирали в состав местного комитета профсоюзов, она была членом общества «Знание», председателем инсти- тутской секции Всероссийского общества охраны памятников истории и культуры, училась в вечернем университете марксизма-ленинизма. В 1969 г. она разработала две экспозиции для Чукотского окружного краеведческого музея по темам «Возникновение человека и развитие человеческого общества» и «Археологические культуры СевероВостока» [Дикова Т. М. Личное дело].

С 1965 г. Т. М. Дикова читала курс по археологии в Магаданском государственном педагогическом институте, руководила археологической практикой студентов, проводила практические занятия в археологическом кружке Дома пионеров. Она являлась одним из авторов коллективного учебного пособия для учащихся 7-8-х классов школ Магаданской области, которое вышло двумя изданиями и в котором ею была написана глава «Первобытнообщинный строй на территории нашего края» (История..., 1976, 1984).

За успехи в работе и общественной жизни коллектива Т. М. Дикова имела благодарности от дирекции СВКНИИ. В 1981 г. ее рекомендовали для представления к почетному званию «Заслуженный ветеран Дальневосточного научного центра».

Безвременная кончина Т. М. Диковой после тяжелой и продолжительной болезни прервала дальнейшие планируемые исследования. Умерла Тамара Митрофановна в Ленинграде 27 ноября 1981 г.

Археологические исследования Т. М. Диковой на южной Камчатке внесли значительный вклад в изучение древнейшей истории ительменов. Она получили достаточно представительные и интересные материалы со стоянок и поселений древних охотников и рыболовов Камчатки. Предложила периодизацию для древних стоянок южной Камчатки (выделены ранний, средний и поздний периоды), охарактеризовала каждый из этих этапов, установила, что айны не обитали постоянно на юге Камчатки, но оказывали определенное влияние на культуру ительменов этой части Камчатки. С именем Т. М. Диковой связано прежде всего изучение археологического прошлого айнов и южных ительменов. Результаты, которые она получила в ходе длительных и трудных экспедиций, заложили прочную основу для дальнейших исследований.

\section{ЛИТЕРАТУРА}

Гусев С. В., Барышев И. Б., Макаров И. В. Исследования Берингийской экспедиции на Камчатке // Археологические открытия 2009 года. М. : Языки славянской культуры, 2013. С. 275-276.

Диков Н. Н., Дикова Т. М. Археологические исследования в зоне затопления водохранилищем Колымской ГЭС в 1971-1973 гг. (краткие предварительные данные) // Краевед. записки. Магадан : Кн. изд-во, 1974. Вып. 10. С. 63-70. 
Диков Н. Н., Дикова Т. М. Исследования на Колыме и Камчатке // Археологические открытия 1971 года. М. : Наука, 1972. С. 252-253.

Диков Н. Н., Дикова Т. М. Памятники каменного века на Камчатке, Колыме и Чукотке // Археологические открытия 1972 года. М. : Наука, 1973. С. 210, 211.

Дикова Т. М. Авачинская многослойная стоянка новый памятник тарьинской культуры на юге Камчатки // Новые археологические памятники Севера Дальнего Востока (по данным Северо-Восточно-Азиатской комплексной археологической экспедиции). Магадан : СВКНИИ ДВНЦ АН СССР, 1979а. С. 82-106.

Дикова Т. М. Археологическая изученность южной Камчатки в связи с айнской проблемой // История и культура народов Северо-Востока СССР : Материалы 3-й сессии Дальневосточных исторических чтений по проблемам истории Северо-Востока СССР. Владивосток, 1976а. С. 21-219.

Дикова T. М. Археологические памятники Магаданской области. Магадан : Кн. изд-во, 1974а. 39 с.

Дикова Т. М. Археология южной Камчатки в связи с проблемой расселения айнов. М. : Наука, 1983. 231 с.

Дикова Т. М. Взаимосвязи между южно-камчатским и американским палеолитом / XIV Тихоокеанский науч. конгресс. Хабаровск, август 1979. Комитет L. : тез. докл. М., 1979б. Т. 2. С. 193.

Дикова Т. М. Древнейшая ткань с южной Камчатки // Природа. 1979в. № 8. С. 120.

Дикова Т. М. Исследования западного побережья южной Камчатки // Археологические открытия 1977 года. М. : Наука, 1978. С. 224-225.

Дикова Т. М. Исследования на юге Камчатки // Археологические открытия 1975 года. М. : Наука, $1976 б$. C. 234, 235.

Дикова T. М. К вопросу о пребывании айнов на мысе Лопатка // Краевед. записки. П.-Камчатский : Камчат. отд-ние Дальневост. кн. изд-ва, 1974б. Вып. 5. C. $150-156$.

Дикова Т. М. Лабретки Южной Камчатки // Новейшие данные по археологии Севера Дальнего Востока (материалы СВАКАЭ). Магадан : СВКНИИ ДВНЦ AH CCCP, 1980. C. 56-63.

Дикова Т. М. Новые данные к характеристике Канчаланской стоянки // История и культура народов Северо-Востока СССР. Магадан, 1964. С. 41-53. (Тр. СВКНИИ ; вып. 8).

Дикова Т. М., Воробьев В. А. Новый памятник бирниркской культуры на севере Чукотки // Записки Чукотского краевед. музея. Магадан : Кн. изд-во, 1973. Вып. 6. С. 9-12.

Дикова Т. М. Основные результаты археологического исследования на Южной Камчатке // Экономические и исторические исследования на СевероВостоке СССР. Магадан : СВКНИИ ДВНЦ АН СССР, 1976в. С. 194-208. (Тр. СВКНИИ ; вып. 67).

Дикова Т. М. Первые находки палеолита на юге Камчатки (м. Лопатка) // Новые археологические памятники Севера Дальнего Востока (по данным Северо-Восточно-Азиатской комплексной археологической экспедиции). Магадан : СВКНИИ ДВНЦ АН СССР, 1979г. С. 29-38.

Дикова T. М. Работы южно-камчатского отряда // Археологические открытия 1973 года. М. : Наука, 1974в. С. 198-199.
Дикова (Кирьяк) М. А. «Железная женщина» (К 70летию со дня рождения Т. М. Диковой) // Колымские ВЕСТИ. 2003. № 22. С. 57-61.

История Магаданской области с древнейших времен до конца XIX века : учеб. пособие для учащихся 7-8-х классов школ Магаданской области. Магадан : Кн. изд-во, 1976. 95 с.

История Магаданской области с древнейших времен до конца XIX века: учеб. пособие для учащихся 7-8-х классов школ Магаданской области : изд. 2-е, перераб. и доп. Магадан : Кн. изд-во, 1984. 100 с.

Кикути Т. Дикова и археология южной Камчатки // Окно. 1985, сентябрь. № 54. С. 2-8. (На яп. языке).

Красков В., Дикова T. Новый памятник приморской культуры на севере Чукотки (полуостров Аачим) // Краевед. записки. Магадан : Кн. изд-во, 1966. Вып. 6. С. 76-83.

Лебединцеев А. И. От древних костров к современности (из истории комплексной гуманитарной лаборатории СВКНИИ) // Наука на Северо-Востоке России (К 100-летию академика Н. А. Шило) : сб. статей; СВКНИИ ДВО РАН. Магадан : СВНЦ ДВО РАН, 2013. 107 с.

Лебединцеев А. И. От прошлого к настоящему // Колымские ВЕСТИ. 2000. № 8. С. 69-73.

СВКНИИ ДВО РАН - 50 лет академической науке на Северо-Востоке России. Магадан : Охотник, 2010. 134 с.

Шило Н. А., Дикова Т. М., Ложкин А. В. Радиоуглеродные датировки древних культур из голоценовых отложений южной Камчатки // ДАН СССР. 1977. T. 237, № 1. C. 180-181.

Dikova T. M. New data on the characteristics of the Kanchalan site // Arctic Anthropology. 1965. Vol. 3, No. 1. P. 91-97.

Dikova T. M. Relationship between the Kamchatkan and American Paleolithic / XIV Pacific Scientific Congress. Khabarovsk, August 1979. Committee L. : abstracts. M., 1979. Vol. 2. P. 194.

Takase K., Lebedintsev A. I. Illustrated Catalogue of Archaeological Materials from Kamchatka in T. M. Dikova Collection Preserved in the North-Eastern Interdisciplinary Scientific Research Institute, Far Eastern Branch, Russian Academy of Sciences (NEISRI FEB RAS), Magadan, Russia. Sapporo : Hokkaido University, 2019. 126 p.

\section{АРХИВНЫЕ МАТЕРИАЛЫ}

Дикова Т. М. Археология Южной Камчатки в связи с проблемой обитания там айнов. Архив СВКНИИ, № $1178.1977 .141 \mathrm{c}$.

Дикова Т. М. Личное дело // Научный архив СевероВосточного комплексного научно-исследовательского института (СВКНИИ ДВО РАН).

Дикова Т. М. Отчет о полевых археологических исследованиях на южной Камчатке в 1973 г. Архив СВКНИИ, № 1066. 1975. 63 с.

Дикова Т. М. Отчет о полевых археологических исследованиях на южной Камчатке в 1975 г. Архив СВКНИИ, № $1138.1976 .70 \mathrm{c}$.

Дикова T. М. Отчет о полевых археологических исследованиях на юге Камчатки в 1972 году. Архив СВКНИИ, № 1020. 1973. 62 с.

Дикова T. М. Сводный отчет об археологических исследованиях в зоне затопления водохранилищем Колымской ГЭС. Архив СВКНИИ, № 1005. 1974. 97 с.

Поступила в редакцию 07.08.2019 2. 


\title{
TAMARA M. DIKOVA : LIFE AND RESEARCH
}

\author{
A. I. Lebedintsev
}

\author{
North-East Interdisciplinary Scientific Research Institute n. a N. A. Shilo, FEB RAS, Magadan
}

The article presents the biographical data and the main results of the scientific activities of Tamara M. Dikova, archaeologist, researcher of the Laboratory of History, Archeology, and Ethnography, NEISRI Far-Eastern Scientific Center of the USSR Academy of Sciences. In 1972-1979, she excavated and investigated a few dozens of archaeological sites in the south of Kamchatka. She studied the Old Itel'men culture, revealed its southern boundary and relations with neighboring cultures. T. M. Dikova offered periodization of ancient sites in southern Kamchatka. She established that the Ainu people had not lived in the south of Kamchatka on a permanent basis but had definitely influenced the Itel'men culture there.

\section{Keywords: history of archaeological research, ancient sites, Ainu, Itel'men, ethnogenesis, ethnic and cultural ties, southern Kamchatka, T. M. Dikova.}

\section{REFERENCES}

Gusev, S. V.; Baryshev, I. B.; Makarov, I. V., 2013, Beringian Expedition Research in Kamchatka, Archeologicheskiye Otkrytiya 2009, Moscow, LRC Publishers, 275-276 [In Russian].

Dikov, N. N.; Dikova, T. M., 1972, Research in Kolyma and Kamchatka, Archeologicheskiye Otkrytiya 1971, Moscow, Nauka, 252-253 [In Russian].

Dikov, N. N.; Dikova, T. M., 1973, Stone Age Sites in Kachatka, Kolyma, and Chukotka, Archeologicheskiye Otkrytiya 1972, Moscow, Nauka, 210-211 [In Russian].

Dikov, N. N.; Dikova, T.M., 1974, Archeological Research in the Flooded Area of the Kolyma Hydroelectric Power Plant in 1971-1973 (Brief Preliminary Data), Kraevedcheskiye Zapiski, 10, Magadan, 63-70 [In Russian].

Dikova (Kiryak), M. A., 2003, "Iron Woman" (On the Occasion of the $70^{\text {th }}$ Birthday of T. M. Dikova), Kolymskiye VESTI, 22, 57-61 [In Russian].

Dikova, T. M., 1964, New Data on the Characteristic of the Kanchalan Site, History and Culture of the Peoples of the USSR North-East, Trudy SVKNII, 8, Magadan, 41-53 [In Russian].

Dikova, T. M., 1965, New Data on the Characteristics of the Kanchalan Site, Arctic Anthropology, 3, 1, 91-97.

Dikova, T. M., 1974a, Archaeological Sites of Magadan Oblast, Magadan [In Russian].

Dikova, T. M., 1974b, On the Issue of the Ainu Presence at Cape Lopatka, Krayevedcheskiye Zapiski, Petropavlovsk-Kamchatsky, 5, 150-156 [In Russian].

Dikova, T. M., 1974c, Works of the South Kamchatka Team, Archeologicheskiye Otkrytiya 1973, Moscow, Nauka, 198-199 [In Russian].

Dikova, T. M., 1976a, Archaeological Coverage of Southern Kamchatka in Connection with the Ainu Problem, History and Culture of the Peoples of the USSR North-East. Proceedings of the $3^{\text {rd }}$ Session of the Far Eastern Historical Readings on the Problems of the History of the USSR North-East, Vladivostok, 211-219 [In Russian].

Dikova, T. M., 1976b, Studies in the South of Kamchatka, Archeologicheskie Otkrytiya 1975, Moscow, Nauka, 234-235 [In Russian].
Dikova, T. M., 1976c, The Main Results of Archaeological Research in Southern Kamchatka, Economic and Historical Research in the North-East of the USSR, Trudy SVKNII, 67, Magadan, SVKNII DVNC AN USSR, 194208 [In Russian].

Dikova, T. M., 1978, Studies of the West Coast of Southern Kamchatka, Archeologicheskiye Otkrytiya 1977, Moscow, Nauka, 224-225 [In Russian].

Dikova, T. M., 1979a, Avacha Multi-Layered Site: New Site of the Tar'ya Culture in Southern Kamchatka, New Archaeological Sites in the North of the Far East (according to the North-East Asian Complex Archaeological Expedition), Magadan, SVKNII DVNC AN USSR, 82-106 [In Russian].

Dikova, T. M., 1979b, Relationships between the Kamchatkan and American Paleolithic, XIV Pacific Scientific Congress. Khabarovsk, August 1979, Committee L : Abstracts, Moscow, 2, 193.

Dikova, T. M., 1979c, Ancient Textile from Southern Kamchatka, Priroda, 8, 120 [In Russian].

Dikova, T. M., 1979d, First Paleolithic Finds in Southern Kamchatka (Cape Lopatka), New Archaeological Sites in the North of the Far East (According to the North-East Asian Complex Archaeological Expedition), Magadan, SVKNII DVNC AN USSR, 29-38 [In Russian].

Dikova, T. M., 1980, Labrets of South Kamchatka, Newest Data on Archaeology of the Northern Far East (Materials of the Northeast Asian Complex Archaeological Expedition), Magadan, SVKNII DVNC AN USSR, 56-63 [In Russian].

Dikova, T. M., 1983, Archaeology of Southern Kamchatka in Connection with the Ainu Settlement Problem, Moscow, Nauka [In Russian].

Dikova, T. M.; Vorobyov, V. A., 1973, New Site of the Birnirk Culture in Northern Chukotka, Zapiski Chukotskogo Krayevedcheskogo Muzeya, VI, Magadan, 9-12 [In Russian].

The History of Magadan Oblast from Ancient Times to the Late XIX Century: Study Guide for the $7^{\text {th }}-8^{\text {th }}$ Grade Students of Magadan Oblast High Schools, 1976, Magadan [In Russian]. 
The History of Magadan Oblast from Ancient Times to the Late XIX Century: Study Guide for $7^{\text {th }}-8^{\text {th }}$ Grade Students of Magadan Oblast High Schools, $2^{\text {nd }}$ Edition, Expanded, 1984, Magadan [In Russian].

Kikuti, T., 1985, Dikova and Archaeology of Southern Kamchatka, Window, September 1985, 54, 2-8 [In Japanese].

Kraskov, V.; Dikova, T., 1966, New Maritime Culture Site in the North of Chukotka (Aachim Peninsula), Krayevedcheskiye Zapiski, VI, Magadan, 76-83 [In Russian].

Lebedintsev, A. I., 2000, From the Past to the Present, Kolymskiye VESTI, 8, 69-73 [In Russian].

Lebedintsev, A. I., 2013, From Ancient Bonfires to the Present (from the History of the NEISRI Interdisciplinary Laboratory of Humanities), Science in the North-East of Russia (On the Occasion of the 100 $0^{\text {th }}$ Anniversary of Academician N. A. Shilo), Selected Articles, NEISRI FEB RAS, Magadan, NESC FEB RAS [In Russian].

NEISRI FEB RAS - 50 years of Academic Science in the North-East of Russia, 2010, Magadan, Okhotnik [In Russian].

Shilo, N. A.; Dikova, T. M.; Lozkin, A. V., 1977, Radiocarbon Dating of Ancient Cultures from Holocene Sediments of Southern Kamchatka, Doklady AS USSR, 237, 1, 180-181 [In Russian].
Takase, K.; Lebedintsev, A. I., 2019, Illustrated Catalogue of Archaeological Materials from Kamchatka in T. M. Dikova Collection Preserved at the North-Eastern Interdisciplinary Scientific Research Institute, Far Eastern Branch, Russian Academy of Sciences (NEISRI FEB RAS), Magadan, Russia, Sapporo, Hokkaido University.

\section{ARCHIVAL MATERIALS}

Dikova, T. M., 1973, Report on Field Research in South Kamchatka in 1972, SVKNII Archives, 1020 [In Russian].

Dikova, T. M., 1974, Preliminary Report on Archaeological Research in the Flooded Area of the Kolyma Hydroelectric Power Plant, SVKNII Archives, 1005 [In Russian].

Dikova, T. M., 1975, Report on Archaeological Field Research in Southern Kamchatka in 1973, SVKNII Archives, 1066 [In Russian].

Dikova, T. M., 1976, Report on Archaeological Field Research in Southern Kamchatka in 1975, SVKNII Archives, 1138 [In Russian].

Dikova, T. M., 1977, Archaeology of Southern Kamchatka in Connection with the Ainu Settlement Problem, SVKNII Archives, 1178 [In Russian].

Dikova, T. M. Personal File, Scientific Archives of the North-Eastern Interdisciplinary Scientific Research Institute (NEISRI FEB RAS) [In Russian]. 